\title{
Associations between farmers market managers' motivations and market-level Supplemental Nutrition Assistance Program Electronic Benefit Transfer (SNAP/EBT) availability and business vitality
}

\author{
Rachel Ward ${ }^{\mathrm{a} *}$ and Deborah Slawson ${ }^{\mathrm{b}}$ \\ East Tennessee State University \\ Qiang $\mathrm{Wu}^{\mathrm{c}}$ and Stephanie Jilcott Pitts ${ }^{\mathrm{d}}$ \\ East Carolina University
}

Submitted April 30, 2015 / Revised July 7 and August 19, 2015 / Accepted August 19, 2015 /

Published online December 8, 2015

Citation: Ward, R., Slawson, D., Wu, Q., \& Pitts, S. J. (2015). Associations between farmers market managers' motivations and market-level Supplemental Nutrition Assistance Program Electronic Benefit Transfer (SNAP/EBT) availability and business vitality. Journal of Agriculture, Food Systems, and Community Development, 6(1), 121-130. http://dx.doi.org/10.5304/jafscd.2015.061.010

Copyright (C) 2015 by New Leaf Associates, Inc.

\begin{abstract}
Farmers markets are promoted to improve access to healthy food for low-income consumers by providing affordable produce via Supplemental Nutrition Assistance Program Electronic Benefit Transfer (SNAP/EBT). Having SNAP/EBT at markets also expands revenue opportunities for participating farmers. Market managers play a key role in implementing SNAP/EBT and promoting

a* Corresponding author: Rachel Ward, DrPH, MPH, Department of Community and Behavioral Health, East Tennessee State University College of Public Health; 104 Lamb Hall, Box 70623; Johnson City, Tennessee 37614 USA; +1-423-439-4592; wardrk@goldmail.etsu.edu

b Deborah Slawson, PhD, RD, Associate Professor, Department of Community and Behavioral Health, East Tennessee State University College of Public Health; 104 Lamb Hall, Box 70623; Johnson City, Tennessee 37614 USA; +1-423-439-4592; slawson@,mail.etsu.edu
\end{abstract}

business opportunities for farmers, yet they are not motivated equally by public health and business goals. There are few studies examining market managers' influence on food access for low-income households and business opportunities for farmers. We examined associations between managers' motivations and (1) food access for low-income households, measured by SNAP/EBT availability, and (2) business vitality, measured by vendor participation. A survey assessing manager motivation, SNAP/EBT availability, and vendor

${ }^{\mathrm{c}}$ Qiang Wu, PhD, Assistant Professor, Department of Biostatistics, East Carolina University College of Allied Health Sciences; 2435D Health Sciences Building; Greenville, North Carolina 27834 USA; +1-252-744-6047; wuq@,ecu.edu

d Stephanie Jilcott Pitts, PhD, Associate Professor, Department of Public Health, East Carolina University; 600 Moye Boulevard, Lakeside Annex 7; Greenville, North Carolina 27834 USA; +1-252-744-5572; jilcotts@ecu.edu 
participation was sent to all market managers $(N=271)$ in North Carolina. Seventy $(26 \%)$ managers completed the survey. Multiple regression models were used to examine the association between managers' motivations to (1) improve access to healthful food and SNAP/EBT availability, and to (2) support business opportunities and total vendor count, weekly vendor count, and the number of vendors who sell only what they produce ("producer-only"). There was no significant association between food access motivation and SNAP/EBT availability, or business motivation and total and weekly vendor count. A high business motivation score was positively associated with having 13 more producer-only vendors at the market. Manager pay was positively correlated with vendor participation, including total vendor, weekly, and producer-only vendor counts. Our results suggest that public health interventions should emphasize the business opportunities offered by SNAP/EBT at farmers' markets, ultimately leveraging market managers' business goals to encourage SNAP/EBT implementation.

\section{Keywords}

Electronic benefit transfer, farmers market, farmers market managers, Supplemental Nutrition Assistance Program, SNAP/EBT

\section{Introduction and Review of SNAP/EBT and Business Opportunities at Farmers Markets} In the United States, policy and environmental change strategies to increase fruit and vegetable access and consumption are promoted to reduce obesity and prevent chronic disease (Centers for Disease Control [CDC], 2010; McCormack, Laska, Larson, \& Story, 2010; Ogden, Carroll, Kit, \& Flegal, 2014; Ward \& Schiller, 2013). Among the CDC's recommended community-level strategies to increase fruit and vegetable access is the introduction of farmers markets (herein referred to as "markets") in communities where fresh produce otherwise is not available (Khan et al., 2009).

\footnotetext{
1 The Supplemental Nutrition Assistance Program is a federally funded nutrition assistance program for low-income individuals and households in the United States. SNAP
}

Farmers markets require less capital than most retail food outlets, and their adaptability to different spaces facilitates their placement in communities where supermarkets do not exist (Briggs, Fisher, Lott, Miller, \& Tessman, 2010).

Simply placing a market in a community does not guarantee that lower-income consumers, who may also be those with highest chronic disease risk, are the ones who will use it to purchase healthy foods (CDC, 2010). There are many barriers to market access, including lack of Supplemental Nutrition Assistance Program/ Electronic Benefit Transfer (SNAP/EBT) ${ }^{1}$ capability, logistical barriers (e.g., hours of business operation not coinciding with preferred shopping times, inconvenient locations, lack of transportation to markets), and cultural barriers (e.g., feeling like an outsider) (Colasanti, Conner, \& Smalley, 2010; Grace, Grace, Becker, \& Lyden, 2007; Suarez-Balcazar, Martinez, Cox, \& Jayraj, 2006). SNAP/EBT availability is one of the most important facilitators of market use by low-income consumers (Briggs et al., 2010). The availability at markets of SNAP/EBT creates a win-win situation wherein low-income consumers can afford farmers market produce, and participating farmers are exposed to a broader customer base. Despite the potential community health and economic benefits of the SNAP/EBT program, relatively few markets operate it. In 2011, only 35\% of markets in the U.S. offered SNAP/EBT (King, Dixit-Joshi, MacAllum, Steketee, \& Leard, 2014). An evaluation of North Carolina's farmers markets found that there are fewer markets with $\mathrm{SNAP} / \mathrm{EBT}$ access in lower-income and minority counties, highlighting the importance a better understanding of the barriers and facilitators to offering SNAP/EBT at markets, particularly in underserved communities (Bullock et al., in press).

Technical and financial support for SNAP/EBT placement at markets is widespread and growing. For example, the North Carolina Community Transformation Grant (NC CTG) farmers market initiative helped markets overcome the cost barrier to operating SNAP/EBT by

Electronic Benefit Transfer (SNAP/EBT) is a program that allows SNAP recipients to authorize the transfer of their SNAP benefits electronically to pay for eligible food products. 
providing technical assistance for SNAP/EBT implementation at markets (Jones \& Bhatia, 2011; Pitts, Acheson, Ward, Wu, McGuirt, Bullock, \& Ammerman, 2015). There remains, however, limited formative research on management-related barriers to SNAP/EBT operations at farmers markets (Cole, McNees, Kinney, Fisher, and Krieger, 2013). Managers are "the building blocks of any successful EBT program" (Briggs et al., 2010 , p. 8). Managers also play critical roles in encouraging business vitality at their markets (as assessed for example by customer counts, vendor participation, and sales) (Stephenson, Lev, \& Brewer, 2007). While all markets are established with the goal of selling food directly to consumers, there is variability in managers' backgrounds and motivations, and consequently, market operations. A mismatch of public health funding goals and market management could undermine significant public investment and derail strategic opportunities to improve public health and business outcomes at farmers markets.

To better understand how managers influence (1) healthy food access for low-income households and (2) business vitality, we examined associations between managers' motivations in their roles, and (Aim 1) food access for low-income households as measured by SNAP/EBT availability, and (Aim 2) business vitality, as measured by total vendor count, weekly vendor count, and the number of vendors who sell only products they produce (herein referred to as "producer-only"), the latter being a measure of a market's emphasis on supporting locally based agriculture (Oberholtzer \& Grow, 2003). We hypothesized that managers motivated to improve community healthy food access would be more likely to have SNAP/EBT available at their markets compared to managers less motivated to improve community food access. We then examined whether managers more motivated by providing business opportunities had greater vendor participation compared to those who were less motivated to provide business opportunities, with the expectation that managers motivated by business would report more vital markets. Answers to these questions could support ongoing investment in market development and enhancements, and provide new insight into the managerial characteristics important for simultaneously achieving public health and business goals at farmers markets.

\section{Applied Research Methods}

\section{Study Setting}

This study took place in North Carolina (NC). In 2011, NC received Community Transformation Grant (CTG) funds, which were provided by the federal Affordable Care Act's Prevention and Public Health Fund. Through the CTG program, the CDC supported awardees across the U.S. as they developed and implemented chronic-disease prevention programs. Using these funds $\mathrm{NC}$ created new markets and promoted enhancements to existing markets, such as SNAP/EBT and transportation for low-income households (Pitts et al., 2013). The current study was part of the NC CTG farmers market evaluation and involved a quantitative survey of a cross-section of NC farmers market managers. All elements of this study were approved by the East Tennessee State University Institutional Review Board, and all participants provided informed consent.

The survey used for this study was informed by a qualitative study described in-depth elsewhere (Ward, 2014) and summarized here to provide context. In spring 2014 focus groups and in-depth interviews were conducted among market managers and farmers participating in markets in southwest Virginia, east Tennessee (TN) and western North Carolina, to gather their perspectives on market operations, the roles and motivations of managers, and managers' influences on market outcomes. We aimed to a hold two focus groups with eight farmers market managers in the region; however, due to scheduling conflicts and geographic spread of the managers, we conducted three focus groups and one in-depth interview. Two focus groups were held at a regional farmers market association meeting in Bristol, TN, in January 2014, with two managers participating in the first focus group, and three managers participating in the second. In February 2014, a third focus group was held with two NC-based farmers market managers, and an in-depth interview was conducted with the eighth manager in a public setting in Asheville, NC. 
In-depth telephone interviews were conducted with farmers participating in markets in the same regions from February to March 2014. Eight farmers participated in the phone interviews, with interview length ranging from 10 to 90 minutes.

The resulting qualitative data were analyzed to develop survey items assessing what motivated managers in their roles. Further details on the data analysis and piloting of the survey items are described elsewhere (Ward, 2014). The items we developed were then combined with items assessing farmers market business vitality from the USDA 2009 Farmers Market Manager Survey (Ragland \& Tropp, 2009).

The target population for the quantitative survey was $\mathrm{NC}$ farmers market managers identified in the North Carolina Fruit and Vegetable Outlet Inventory (FVOI). The FVOI is a directory of all fruit and vegetable markets in the state, developed as part of the NC CTG evaluation. Local health department staff gather and update the data yearly. Because this was a pilot study, we did not conduct a power analysis, but we attempted to survey all farmers market managers in $\mathrm{NC}$ who were included in the FVOI. To obtain the managers' contact information, all outlets categorized as "farmers markets" and their corresponding managers and contact information (i.e., email addresses, phone numbers, and mailing addresses) were queried. This search yielded 271 managers, who were then contacted by email, or telephone if their e-mail address was not available, and invited to participate in the web-based survey (Survey Monkey, Palo Alto, California). Between May 14 and May 25, 2014, managers with an email address received two reminder e-mails, and managers without an email address received at least one reminder phone call. To increase participation, a second wave of data collection was conducted from July 22 to August 15, 2014. This involved bulk postal mailing of 200 surveys to managers who did not respond in the first wave of data collection. Participants were provided with the option of completing a hard copy of the survey and returning it in a prepaid envelope, or completing the survey online. All respondents were given US $\$ 10$ as an incentive upon survey completion.

\section{Community Food Access and Business Motivation}

The two independent variables were dichotomous: (1) high or low community food access motivation, and (2) high or low business motivation. These categorizations were not mutually exclusive.

To develop the food access motivation variable, participants were asked: "Which aspects of your job as a farmers market manager do you believe to be MOST important?” Participants were asked to rank the list of six aspects of their roles as managers in order of importance (from 1 as most important to 6 as least important) (Table 1). If participants ranked "making healthy food more

\section{Table 1. Distribution of Survey Items Used To Create Binary Food Access and Business Motivation Categorization Among North Carolina Farmers Market Managers ( $n$ ranged from 63 to 67 )}

\begin{tabular}{|c|c|c|c|c|}
\hline Food access categorization, $n=63$ & \multicolumn{4}{|c|}{$n(\%)$} \\
\hline Low food access motivation & \multicolumn{4}{|c|}{$25(39.7)$} \\
\hline High food access motivation & \multicolumn{4}{|c|}{$38(60.3)$} \\
\hline Item responses used to create categorization & $\mathrm{n}$ & Mean (SD) & Variance & Range \\
\hline Role: Making food more affordable a & 59 & $3.47(1.39)$ & 1.94 & $1-6$ \\
\hline Role: Making food more accessible a & 63 & $4.36(1.43)$ & 2.04 & $1-6$ \\
\hline Business motivation categorization, $n=67$ & \multicolumn{4}{|c|}{$\mathrm{N}(\%)$} \\
\hline Low business motivation & \multicolumn{4}{|c|}{$19(28.4)$} \\
\hline High business motivation & \multicolumn{4}{|c|}{$48(71.6)$} \\
\hline Item responses used to create categorization & $\mathbf{n}$ & Mean (SD) & Variance & Range \\
\hline Role: Supporting local agriculture & 63 & $4.83(1.23)$ & 1.50 & $2-6$ \\
\hline Role: Supporting local artisans & 64 & $2.20(1.22)$ & 1.49 & $1-5$ \\
\hline Role: Supporting the local economy in general & 63 & $3.19(1.67)$ & 2.80 & $1-6$ \\
\hline
\end{tabular}

$n=$ sample size; $\mathrm{SD}=$ standard deviation

a Possible response range 1-6 (1-least important, 6-most important) 
available in my community" or "making food more accessible in my community" in one of the top two most important roles, they were categorized as "high food access motivation." Thirty-eight (60\%) had high food access motivation, and while the rest had low food access motivation.

To develop the business motivation variable, participants were categorized as having "high business motivation" if they ranked "supporting local agriculture," "supporting business in general," or "supporting local artisans" as one of their top 2 most important roles. The term "local" was not defined for participants, and thus managers were given freedom to interpret the term based upon their own experience. Forty-eight (72\%) had high business motivation, and the rest had low business motivation.

\section{SNAP/EBT Availability}

The dependent variable in the model examining food access motivation was SNAP/EBT availability at the market. To measure SNAP/EBT availability, managers were asked: "In 2013, was SNAP/ EBT handled through a market-wide program? For example, did the market operate SNAP/EBT centrally (Yes or No)?”

\section{Business Vitality}

The dependent variables in the model examining business motivation were total vendor count, weekly vendor count, and producer-only vendor count. Total vendor count was a continuous variable developed from the response to the question "How many vendors participated at your market in 2013?" Weekly vendor count was a continuous variable developed from the response to the question "On average, how many vendors participated at your market each week in 2013?” Producer-only vendor count was a continuous variable developed from the response to the question "In 2013, how many vendors at your market only sold farm products they produced themselves?" These items were from the USDA 2009 Farmers Market Manager Survey (Ragland \& Tropp, 2009).

\section{Covariates}

Covariates were selected based on characteristics of farmers market managers and markets that were hypothesized to influence market outcomes (SNAP/EBT availability and business vitality) (Stephenson et al., 2007). Manager characteristics included: whether the manager was paid to manage the market (Yes or No), the manager's age (in years), and the manager's years of experience managing the market. Market characteristics included: the number of years in operation (including 2014), and the number of volunteers who work at the market (including the respondent, if a volunteer).

\section{Data Analysis}

Data were analyzed in SPSS version 21 (SPSS IBM, New York). Descriptive statistics were used to summarize participant and market characteristics. Binary logistic regression was used to examine the association between the likelihood that participants have SNAP/EBT at their farmers markets (dependent variable) and their community food access motivation (independent variable, high or low) (Model 1). Backwards selection was used to find the most parsimonious models. Models were adjusted for manager characteristics (age, pay status, and years managing the market, Model 2) and further adjusted for market characteristics (volunteers and years in operation, Model 3). A final, adjusted model retained only the covariates that were significantly associated with the dependent variable $(p<.05)$ (Model 4).

Separate, crude (Model 1) multiple linear regression models were used to examine associations between continuous business vitality measures and the dichotomous business motivation (independent variable, high or low). These models were also adjusted for manager characteristics (age, pay status, and years managing the market, Model 2) and further adjusted for market characteristics (volunteers and years in operation, Model 3). Final, adjusted models retained only the covariates that were significantly associated with the dependent variable $(p<.05)$ (Model 4). Participants with missing data for either the food access motivation or business motivation scores were excluded from regression analysis.

\section{Results}

Eighty (80) managers responded to the survey, including three duplicate responses that were 
removed. Seventy (70) managers responded beyond the first two questions and were thus included for analysis (26\% response rate) (Table 2). The average participant age was 48 years (range: 22-88 years). The majority of managers were paid to operate their markets $(59 \%)$ and had an average of 5 years (range: 1-20 years) of experience managing the market. The average market had operated for 11 years (range: $1-41$ years), and had an average of 8 volunteers (range: $0-300$ volunteers). Markets had an average of 31 vendors in 2013 (range: 1150 vendors), 19 vendors weekly (range: $1-65$ vendors), and 17 producer-only vendors per season (range: $0-125$ vendors). An average of 353 (range: 10-3,000 customers) customers visited the markets each week. Thirteen participants $(19 \%)$ reported SNAP/EBT availability at their markets.

For the first aim, the association between community food access motivation and SNAP/EBT availability was not significant in the crude or adjusted models, suggesting that there was no association between community food access motivation and SNAP/EBT availability (Table 3). The number of years of operation was significantly associated with SNAP/EBT availability, such that markets that had been in operation for a longer time were more likely to have SNAP/EBT available (Model 3: OR 1.12, SE .04). For the second aim, the association between business motivation and total vendor count and weekly vendor count was not statistically significant in the crude and adjusted models (Table 4). The association between business motivation and producer-only vendor count, however, was significant in the crude model (Model 1: $\beta$ 13.05, SE 5.67) and when adjusted for manager characteristics (Model 2: $\beta$ 12.93, SE 5.67) and manager pay (Model 4: $\beta$ 12.55, SE 5.45). Having a high business motivation score was significantly associated with an average increase of 13 producer-only vendors per season. In addition, manager pay status was significantly associated with the three business outcomes of interest (total vendor count, vendors per week, and producer-only vendor count), such that markets with paid managers had better business outcomes compared to markets with nonpaid (volunteer) managers.

\section{Discussion}

Managers' motivations to improve access to healthful foods in their communities were not associated with SNAP/EBT availability at their markets. This suggests that the relationship between being motivated by community food access issues and providing SNAP/EBT is not as straightforward as was initially hypothesized. There are a number of necessary steps between being motivated to mitigate

\section{Table 2. Characteristics of North Carolina Farmers Market Managers} and the Markets They Manage, $n=70$

\begin{tabular}{lccc}
\hline & $n$ & Mean (SD) & Range \\
\hline Manager characteristics & & & \\
\hline Age (years) & 67 & $47.8(15.0)$ & $22-88$ \\
Years managing the market & 68 & $4.9(4.2)$ & $1-20$ \\
Paid; $n$ (\%) & 69 & $41(59.4)$ & \\
\hline Market characteristics & & & \\
\hline Volunteers (number) & 63 & $7.7(37.6)$ & $0-300$ \\
Years in operation & 67 & $10.9(9.8)$ & $1-41$ \\
Presence of SNAP/EBT; $n$ (\%) & 67 & $13(19.4)$ & \\
Presence of vendors who operate SNAP/EBT; $n$ (\%) & 68 & $8(11.6)$ & $0-8000$ \\
Value of market SNAP/EBT sales, 2013 (in US\$) & 12 & $1958(3107)$ & $0-900$ \\
SNAP/EBT customer count, 2013 & 10 & $131.3(277.3)$ & $3-150$ \\
Total number of vendors, 2013 & 69 & $30.9(27.1)$ & $2-65$ \\
Average number of vendors per week, 2013 & 69 & $19.4(15.9)$ & $0-125$ \\
Number of producer-onlya vendors, 2013 & 67 & $17.5(20.9)$ & $10-3000$ \\
Average number of customers per week, 2013 & 54 & $358.9(512.5)$ & \\
\hline
\end{tabular}

$n=$ sample size; $\mathrm{SD}=$ standard deviation

a Producer-only is defined as vendors having produced food or farm products themselves. 
food access barriers in the community and actually implementing SNAP/EBT. Market finances, manager pay, manpower, vendor participation, and the community context are just several of many factors that contribute to the introduction of SNAP/EBT in farmers markets (Appalachian Sustainable Agriculture Project [ASAP] Local Food Research Center, 2012). For example, a recent evaluation of the

Table 3. Association Between North Carolina Farmers Market Managers' Food Access and Business Motivation Scores and Supplemental Nutrition Assistance Program Electronic Benefit Transfer (SNAP/EBT) Availability and Business Vitality ( $n$ ranges from 54 to 66, depending on the model)

\begin{tabular}{|c|c|c|c|c|}
\hline Model & $n$ & OR & SE & $P$ \\
\hline \multicolumn{5}{|c|}{$\begin{array}{l}\text { Regression of SNAP/EBT Availability on Food Access Motivation Score } \\
\text { Among North Carolina Farmers Market Managers }\end{array}$} \\
\hline Model $1^{\mathrm{a}}$ & 62 & 1.33 & 0.68 & 0.67 \\
\hline Model $2^{b}$ & 60 & 1.57 & 0.69 & 0.51 \\
\hline Model $3^{c}$ & 54 & 2.08 & 0.87 & 0.40 \\
\hline Model $4^{d}$ & 60 & 1.89 & 0.78 & 0.41 \\
\hline \multicolumn{5}{|c|}{$\begin{array}{l}\text { Regression of Total Vendor Count on Business Motivation Score Among } \\
\text { North Carolina Farmers Market Managers }\end{array}$} \\
\hline Model $1^{a}$ & 64 & 11.76 & 7.31 & 0.11 \\
\hline Model $2^{b}$ & 62 & 12.79 & 6.89 & 0.07 \\
\hline Model $3^{c}$ & 54 & 10.78 & 7.91 & 0.18 \\
\hline Model $4^{\mathrm{e}}$ & 65 & 11.18 & 6.67 & 0.09 \\
\hline
\end{tabular}

Regression of Average Number of Vendors per Week on Business Motivation Score Among North Carolina Farmers Market Managers

\begin{tabular}{lllll}
\hline Model $1^{\mathrm{a}}$ & 66 & 6.92 & 4.30 & 0.11 \\
Model 2 $^{\mathrm{b}}$ & 64 & 6.82 & 3.95 & 0.09 \\
Model 3c $^{\mathrm{c}}$ & 56 & 4.02 & 4.33 & 0.36 \\
Model 4 $^{\mathrm{f}}$ & 64 & 5.82 & 3.82 & 0.13 \\
\hline
\end{tabular}

Regression of Local Vendor Count on Business Motivation Score Among North Carolina Farmers Market Managers

\begin{tabular}{lllll}
\hline Model $1^{\mathrm{a}}$ & 64 & 13.05 & 5.67 & $0.03^{*}$ \\
Model 2 $^{\mathrm{b}}$ & 62 & 12.93 & 5.67 & $0.03^{*}$ \\
Model 3c $_{\text {Model 4 }}^{\mathrm{e}}$ & 54 & 11.41 & 6.62 & 0.09 \\
\hline
\end{tabular}

$n=$ sample size; $\mathrm{OR}=$ odds ratio; $\beta=$ beta coefficient; $\mathrm{SE}=$ standard error, $P=p$-value

a Unadjusted model

b Adjusted for manager characteristics (manager's age, years managing the market, and manager pay status (yes/no; yes is referent category)

${ }^{c}$ Adjusted for market characteristics (number of volunteers, years in operation)

dAdjusted for years in operation

e Adjusted for manager pay status (yes/no; yes is referent category)

${ }^{\mathrm{f}}$ Adjusted for manager pay status and years in operation

* Statistically significant at $p<.05$
SNAP/EBT program in 10 Michigan farmers maround that SNAP/EBT availability increased among SNAP recipients, and participating managers were positive and supportive of the program. 年, only $29 \%$ of participating vendors believed the SNAP/EBT was successful, and only tinue participating in the SNAP/EBT program at their market (Krokowski, 2014).

Markets that had been established for more years were more likely to have SNAP/EBT available. This may be a result of older markets having more resources, such as established management with the time and experience to oversee a SNAP/ EBT program. Managers of older markets may also have a better understanding of the demand for SNAP/EBT in their communities and among their vendors, and thus be more likely to introduce the program if they think it will be successful.

The relationships between business motivation and total and average weekly vendor count were not significant. However, having a high business motivation score was significantly associated with an increase of 13 producer-only vendors per season. This finding indicates that managers who are motivated to support business may facilitate greater opportunities for produceronly vendors through their market compared to managers with a low business motivation. It may also be that managers with higher business motivation scores are also 
more likely to know and accurately report market vitality data like vendor participation. Market managers who were paid had greater vendor participation than unpaid managers. This reflects findings from a study of farmers market failure in Oregon, which found a positive association between manager pay and administrative revenue generated from vendor fees at markets (Stephenson, Lev, \& Brewer, 2006). Managers who are paid are able to invest more time into operating the market, and therefore are more likely to have markets that attract customers and vendors. Established markets are also more likely to have the funds to pay their managers compared to newer markets.

Managers who are not highly motivated by promoting food access but are motivated by promoting local business opportunities could be motivated to offer SNAP/EBT if they become more knowledgeable about the economic benefits of participation. In 2010, farmers market sales represented only $0.01 \%$ of all SNAP spending (McNutt, Price, and Dixit-Joshi, 2012). The potential customer base and sales potential for markets that expand their SNAP/EBT base is significant.

A key limitation of this study was the small sample size, and thus the study is not generalizable to all markets in North Carolina. Multiple attempts were made to contact managers directly using email, telephone calls, and paper survey mailings. The response rate of $26 \%$ may be due to incomplete, outdated (due to manager turnover, changes in phone numbers, etc.), or inaccurate manager contact information provided in the FVOI, or market managers being busy during the market season. These factors may have introduced response bias whereby managers who were more likely to be involved or familiar with the NC CTG were also more likely to have responded to the survey. Another barrier to recruitment may have been the university's requirement of participants to provide their Social Security number to receive the incentive payment, which was met with reticence by some managers. The FVOI does not include data on market managers apart from contact information, and therefore we were limited in our ability to compare respondents to nonrespondents. Future studies could aim to increase the sample size by removing the Social Security number requirement for payment and recruiting managers during the market's off-season. Recruiting and surveying managers in person may also improve the sample size; however, this method was costprohibitive for the current study.

Another limitation was the poor reliability of certain indicators of SNAP/EBT participation and business vitality. Specifically, vendor and SNAP/ EBT sales and SNAP/EBT customer counts would have been important outcomes to examine for this study, but they tend to be unreliable as most managers do not seem to document them. It will be important to develop a standard method for collecting these important indicators of market reach and impact, as these metrics could be useful for longitudinal evaluations of farmers market interventions. For example, there is ongoing development of a mobile device application so that various farmers market evaluation metrics can be entered directly into a mobile device (such as an iPhone) and uploaded into a standardized database (Freedman, 2014).

\section{Conclusion}

Farmers markets are uniquely positioned to meet both the healthy food access needs and economic opportunities of their communities. Currently, there is a gap in the understanding of how farmers market managers can influence these areas of opportunity. This study serves as a starting point for elucidating specific managerial characteristics that could converge with other important facilitators to maximize the potential of farmers markets to simultaneously improve food access for customers and business opportunities for farmers. Future studies with a larger sample of managers should aim to clarify which characteristics influence these opportunities. As our study suggests, this could lend more insight into how managers' business motivation and pay influence vendor participation at farmers markets. We did not find a relationship between managers' motivations and SNAP/EBT availability. Additional work is needed to identify barriers to offering SNAP/EBT at farmers markets, particularly among managers who perceive food access issues as being important, but do not operate markets with SNAP/EBT. Addressing managers' motivations, whether they are business- 
oriented, healthy food access-oriented, or both, will be critical to improving the food environment through farmers markets.

\section{Acknowledgements}

The authors gratefully acknowledge the North Carolina Community Transformation Grant farmers market strategy evaluation team for their assistance with data collection. We also appreciate the guidance provided by Dr. Mary Ann Littleton and Dr. Liang Wang throughout this study, the qualitative data analysis support provided by Natalie Walker, and the feedback offered by Jared McGuirt and Dr. David Blackley. Finally, we would like to thank the farmers and farmers market managers from North Carolina, East Tennessee, and Virginia who contributed to this work.

\section{References}

Appalachian Sustainable Agriculture Project (ASAP) Local Food Research Center. (2012). Farmers markets for all: Exploring barriers and opportunities for increasing fresh food access by connecting low-income communities with farmers markets. Retrieved from http://asapconnections. org/downloads/asap-farmers-markets-for-all-fullreport.pdf

Briggs, S., Fisher, A., Lott, M., Miller, S., \& Tessman, N. (2010). Real food, real choice: Connecting SNAP recipients with farmers markets. Portland, Oregon: Community Food Security Coalition and Cockeysville, Maryland: Farmers Market Coalition. Retrieved from http://cclhdn.org/wp-content/uploads/ 2013/02/RealFoodRealChoice SNAP Farmers Markets.pdf

Bullock, S., Jilcott Pitts, S. B., Listenfelt, B., McGuirt, J. T., Stanley, K., Beth, D., Kolbe, M. B., Rushing, J., Qiang, W., Ward, R. W., Mayo, M. L., Dortche, C. J. M., \& Ammerman, A. (in press). Availability of farmers' markets and supplemental nutrition assistance program/electronic benefit transfer systems and associations with rurality, poverty, race/ethnicity, and obesity among North Carolina counties. Journal of Hunger and Environmental Nutrition.

Centers for Disease Control and Prevention [CDC]. (2010). State-specific trends in fruit and vegetable consumption among adults_-United States, 20002009. Morbidity and Mortality Weekly Report, 59(35),
1125-1164. Retrieved from http://www.cdc.gov/ mmwr/pdf/wk/mm5935.pdf

Colasanti, K. J. A., Conner, D., \& Smalley, S. B. (2010). Understanding barriers to farmers' market patronage in Michigan: Perspectives from marginalized populations. Journal of Hunger \& Environmental Nutrition, 5(3), 316-338. http://dx.doi.org/10.1080/19320248.2010.504097

Cole, K., McNees, M., Kinney, K., Fisher, K., \& Krieger, J. W. (2013). Increasing access to farmers markets for beneficiaries of nutrition assistance: Evaluation of the farmers market access project. Preventing Chronic Disease, 10, 1-14. http://dx.doi.org/10.5888/pcd10.130121

Freedman, D. A. (2014). FM Tracks (Version 1) [Mobile application software].

Grace, C., Grace, T., Becker, N., \& Lyden, J. (2007). Barriers to using urban farmers' markets: An investigation of food stamp clients' perceptions. Journal of Hunger \& Environmental Nutrition, 2(1), 5575. http://dx.doi.org/10.1080/19320240802080916

Jones, P., \& Bhatia, R. (2011). Supporting equitable food systems through food assistance at farmers' markets. American Journal of Public Health, 101(5), 781-783. http://dx.doi.org/10.2105/AJPH.2010.300021

Khan, L. K., Sobush, K., Keener, D., Goodman, K., Lowry, A., Kakietek, J., \& Zaro, S. (2009).

Recommended community strategies and measurements to prevent obesity in the United States. Morbidity and Mortality Weekly Report, 58(RR7), 1-26. PMID: 19629029

King, M., Dixit-Joshi, S., MacAllum, K., Steketee, M., \& Leard, S. (2014). Farmers Market Incentive Provider Study. Alexandria, Virginia: U.S. Department of Agriculture, Food and Nutrition Service. Retrieved from http://www.fns.usda.gov/research-andanalysis

Krokowski, K. (2014). Evaluating the economic and nutritional benefits and program challenges of EBT programs at farmers' markets. Journal of Agriculture, Food Systems, and Community Development, 4(2), 37-44. http://dx.doi.org/10.5304/jafscd.2014.042.011

McCormack, L. A., Laska, M. N., Larson, N. I., \& Story, M. (2010). Review of the nutritional implications of farmers' markets and community gardens: A call for evaluation and research efforts. Journal of the American Dietetic Association, 110(3), 399-408. http://dx.doi.org/10.1016/j.jada.2009.11.023 
McNutt, S., Price, S., \& Dixit-Joshi, S. (2012). Nutrition assistance in farmers markets: Understanding current operations - Formative research findings, final report. Alexandria, Virginia: U.S. Department of Agriculture, Food and Nutrition Service, Office of Research and Analysis. Retrieved from http://www.fns.usda.gov/sites/default/files/ FarmersMarkets.pdf

Oberholtzer, L., \& Grow, S. (2003). Producer-only farmers' markets in the Mid-Atlantic region: A survey of market managers. Arlington, Virginia: Henry A. Wallace Center for Agricultural and Environmental Policy at Winrock International.

Ogden, C. L., Carroll, M. D., Kit, B. K., \& Flegal, K. M. (2014). Prevalence of childhood and adult obesity in the United States, 2011-2012. Journal of the American Medical Association, 311(8), 806-814. http://dx.doi.org/10.1001/jama.2014.732

Pitts, S. B. J., Acheson, M. L. M., Ward, R. K., Wu, Q., McGuirt, J. T., Bullock, S. L., \& Ammerman, A. S. (2015). Disparities in healthy food zoning, farmers' market availability, and fruit and vegetable consumption among North Carolina residents. Archives of Public Health, 73(1), 1-9.

Ragland, E., \& Tropp, D. (2009). USD A National Farmers Market Manager Survey, 2006. Washington, D.C.: United States Department of Agriculture, Agricultural Marketing Service. http://dx.doi.org/10.9752/MS037.05-2009
Stephenson, G. O., Lev, L., \& Brewer, L. (2006). When things don't work: Some insights into why farmers' markets close. Corvallis, Oregon: Oregon State University, Extension Service. Retrieved from http://smallfarms.oregonstate.edu/sites/default/ files/small-farms-tech-report/eesc 1073.pdf

Stephenson, G. O., Lev, L., \& Brewer, B. (2007). Understanding the link between farmers' market size and management organization. Corvallis, Oregon: Oregon State University, Extension Service. Retrieved from http://ir.library.oregonstate.edu/xmlui/handle/ $\underline{1957 / 8438}$

Suarez-Balcazar, Y., Martinez, L. I., Cox, G., \& Jayraj, A. (2006). African Americans' views on access to healthy foods: What a farmers' market provides. Journal of Extension, 44(2).

Ward, B. W., \& Schiller, J. S. (2013). Prevalence of multiple chronic conditions among US adults: Estimates from the National Health Interview Survey, 2010. Preventing Chronic Disease, 10, 1-15. http://dx.doi.org/10.5888/pcd10.120203

Ward, R.K. (2014). Examining the influence of farmers' market motivations on access to healthful foods and business opportunities for farms (Unpublished doctoral dissertation). East Tennessee State University College of Public Health, Johnson City, Tennessee. 